\title{
Food Color Additives in the US Food Supply: Review of Neurobehavioral Safety
}

\author{
G Craig Llewellyn, PhD ${ }^{1 *}$, J Kim Penberthy, $P h D^{2}$ and Julia M Parker, $B A^{1}$ \\ ${ }^{1}$ Toxicology Regulatory Services, USA \\ ${ }^{2}$ University of Virginia School of Medicine, USA
}

\begin{abstract}
Currently approved food additives, including color additives, have a long history of safe use in human consumables. Many food additives are added to increase the flavor or other sensory appeal of food items and have typically been viewed as enhancing the experience of eating or drinking. Research on the impact of food color additives (FCAs) upon neurobehavior, especially focusing on hyperactive behavioral symptoms in children and adolescents, began in the mid1970s in the United States (US) with animal and human studies. Interest in the impact of FCAs on behavior and especially neurobehavior in children and adolescents with attention-deficit/hyperactivity disorder (ADHD) symptoms has increased over time. We examined scientific evidence on the relationship of the Food and Drug Administration (FDA) approved FCAs and behaviors in children and adolescents with ADHD symptoms and in laboratory animals. Current literature on human and animal research with a focus on meta-analyses and systematic reviews was reviewed. Our results indicate that published human studies from the past decade do not offer a strongor reliable explanation of the impact of FCA presence or elimination on ADHD symptoms in children and adolescents. Non-clinical studies involving animals included exposures to FCAs that was considerably greater than amounts estimated to be consumed in the diets of humans either alone or in mixtures and found that the magnitude of behavioral changes observed have been small, inconsistent, and not dose-dependent in nature. Limitations of our review and potential for future research are presented herein.
\end{abstract}

\section{Keywords}

Food color additives, Artificial colors, ADHD, Neurobehavior, Food dyes, Pediatric

\begin{abstract}
Abbreviations
ADHD: Attention-Deficit/Hyperactivity Disorder; CDC: Center for Disease Control and Prevention; Cl: Confidence Interval; DSM: Diagnostic and Statistical Manual of Mental Disorders; EUNETHYDIS: European Network for Hyperkinetic Disorder; EFSA: European Food Safety Authority; FAC: Food Advisory Committee; FAO: Food and Agriculture Organization of the United Nations; FDA: Food and Drug Administration; FCA: Food color additive; i.p: Intra-peritoneal; JECFA: Joint FAO/ WHO Expert Committee on Food Additives; $\mathrm{mg} / \mathrm{kg}$ bw/day: Milligrams [test article] per kilogram body weight per day; N/A: Not Applicable; NOAEL: No Observed Adverse Effects Level; RCT: Randomized Clinical Trial; US: United States; UMass: University of Massachusetts; WHO: World Health Organization
\end{abstract}

\section{Introduction}

Food additives, including FCAs, have been regulated since at least the thirteenth century [1]. Modern FCAs are used by food product developers to indicate palatability, or tastiness, of food and beverage products. Colors are also added to ensure an even, consistent appearance and to replace intrinsic color lost during processing, and create visual cues that match flavoring cues, all to help food and beverage products meet the expectations of consumers. FCAs, as well as all food additives, must be demonstrated and determined to be safe for their intended use in foods prior to their addition to the food supply.

One specific concern associated with certain FCAs has been the potential for the induction of or worsening of neg- ative neurobehavioral effects, specifically hyperactivity behaviors in children $[2,3]$. A particular focus of research has been associated with consumption of FCAs and potential for negative neurobehavioral effects in children diagnosed with Attention-Deficit/Hyperactivity Disorder (ADHD) or symp-

*Corresponding author: G Craig Llewellyn, PhD, Toxicology Regulatory Services, 154 Hansen Rd., Suite 201 Charlottesville, VA 22911 USA, Tel: 434-977-5957, Fax: 434-977-1856

Accepted: August 25, 2020

Published online: August 27, 2020

Citation: Llewellyn GC, Penberthy JK, Parker JM (2020) Food Color Additives in the US Food Supply: Review of Neurobehavioral Safety. J Pediatr Neurol Neurosci 4(1):55-72 
Citation: Llewellyn GC, Penberthy JK, Parker JM (2020) Food Color Additives in the US Food Supply: Review of Neurobehavioral Safety. J Pediatr Neurol Neurosci 4(1):55-72

Table 1: Food color additives (FCAs) and their synonyms reviewed within this evaluation.

\begin{tabular}{|c|c|c|}
\hline FCAs subject to certification in the USA & Synonyms & Comments \\
\hline \multicolumn{3}{|c|}{ Within scope of this manuscript } \\
\hline FD \& C Blue No. 1 & $\begin{array}{l}\text { Brilliant Blue FCF } \\
\text { CI Blue } 2 \\
\text { INS } 133\end{array}$ & \\
\hline FD \& C Blue No. 2 & $\begin{array}{l}\text { Indigo Carmine/Indigotine } \\
\text { Cl Blue } 1 \\
\text { INS } 132\end{array}$ & \\
\hline FD \& C Red No. 3 & $\begin{array}{l}\text { Erythrosine } \\
\text { INS } 127\end{array}$ & \\
\hline FD \& C Red No. 40 & $\begin{array}{l}\text { Allura Red AC } \\
\text { CI Red } 17 \\
\text { INS } 129\end{array}$ & Involved in Southampton study \\
\hline FD \& C Yellow No. 5 & $\begin{array}{l}\text { Tartrazine } \\
\text { CI Yellow } 4 \\
\text { INS } 102\end{array}$ & Involved in Southampton studies \\
\hline FD \& C Yellow No. 6 & $\begin{array}{l}\text { Sunset Yellow FCF } \\
\text { CI Yellow } 3 \\
\text { INS } 110\end{array}$ & Involved in Southampton studies \\
\hline FD \& C Green No. 3 & $\begin{array}{l}\text { Fast Green FCF } \\
\text { CI Food Green } 3 \\
\text { INS } 143\end{array}$ & \\
\hline \multicolumn{3}{|c|}{ Out of scope for this evaluation } \\
\hline Orange B & $\begin{array}{l}\mathrm{Cl} \text { Orange } 17 \\
\text { No INS Number }\end{array}$ & $\begin{array}{l}\text { Restricted use only per CFR; not included in FDA } \\
\text { exposure assessment; negligible human intake }\end{array}$ \\
\hline Citrus Red No. 2 & $\begin{array}{l}\text { CI Solvent Red } 80 \\
\text { INS } 121\end{array}$ & $\begin{array}{l}\text { Restricted use only per CFR; not included in FDA } \\
\text { exposure assessment; negligible human intake }\end{array}$ \\
\hline N/A & $\begin{array}{l}\text { Carmoisine } \\
\text { INS } 122\end{array}$ & $\begin{array}{l}\text { Involved in Southampton studies but not approved } \\
\text { for use in the US }\end{array}$ \\
\hline N/A & $\begin{array}{l}\text { Ponceau 4R } \\
\text { INS } 124\end{array}$ & $\begin{array}{l}\text { Involved in Southampton studies but not approved } \\
\text { for use in the US }\end{array}$ \\
\hline
\end{tabular}

toms thereof [4]. Observational studies regarding diet and ADHD symptoms in youth have appeared in the literature over the past forty-plus years. Beginning with the work of Dr. Ben Feingold [2], a number of publications reported on dietary intake patterns and the impact on ADHD symptoms. In 2004 and 2007, two studies were published by researchers at Southampton University on the topic of FCAs and hyperactive symptoms in children $[3,5]$. These research studies are commonly referred to as the Southampton studies, and were responsible for an increased interest in the impact of FCAs on ADHD symptoms and behaviors. The Southampton studies evaluated mixtures of food additives, including FCAs approved for use in the United States (US), Allura Red 40, Tartrazine, and Sunset Yellow FCF (see Table 1 for synonyms); FCAs not approved for use in the US, Carmoisine and Ponceau $4 R$, and the preservative sodium benzoate.

The current review will focus on an assessment of the information associated with neurobehavioral effects of seven of the nine synthetic FCAs approved for use in the US because only seven are FD \& $C$ food colors approved for wide use in foods by the FDA for ingestion, i.e. FD \& C Blue No. 1, FD \& C Blue No. 2, FD \& C Red No. 3, FD \& C Red No. 40, FD \& C Yellow No. 5, FD \& C Yellow No. 6, and FD \& C Green No. 3 (see Table 1). The other two colors approved by the FDA, i.e. Orange B and Citrus Red No. 2, are only authorized for limited use as external colorants and will not be covered in this review. Of the colors utilized in the Southampton studies, three are FD \& C color additives approved for use in the US and included in this evaluation (i.e. FD \& C Yellow No. 6, FD \& C Yellow No. 5, and FD \& C Red No. 40). The remainder of the FD \& C colors (FD \& C Blue No. 1, FD \& C Blue No. 2, FD \& C Red No. 3, and FD \& C Red No. 3) were never studied in the Southampton studies or similar human trials such as Lok, et al. [6]. This review examines the research literature on the relationship of all FD \& C FCAs and behavior in children and adolescents with diagnosed ADHD and ADHD symptoms, as well as the literature as it relates to neurobehavioral changes in laboratory animals. 
Citation: Llewellyn GC, Penberthy JK, Parker JM (2020) Food Color Additives in the US Food Supply: Review of Neurobehavioral Safety. J Pediatr Neurol Neurosci 4(1):55-72

\section{Landmark studies}

The Southampton studies both utilized a randomized, double-blinded, placebo-controlled crossover trial design to test whether the intake of artificial food color and additives affected childhood behavior. In both studies, the test article (i.e. two mixtures of colors and sodium benzoate) and placebo mix were administered via a juice drink. The children studied were not clinically diagnosed with ADHD, but instead were a convenience sample classified either as hyperactive or not, based only on a rating scale.

In Bateman, et al. [5] parents were asked to remove FCAs of interest from their children's diets for a month. Then, in a 'double-blind challenge' phase, the children were each given a daily fruit drink for a week, with half of the children given drinks containing the additives and the other half given a similar non-additive drink. Parents and children were blind in this part of the study and did not know which drink they had. The results of Bateman, et al. [5] revealed no significant difference in behavior between the two groups who received the FCA or the placebo as assessed by trained and blinded psychologists. However, the hyperactive ratings significantly increased on active challenge compared to placebo when rated by parents, who were blinded to the treatment. The authors provided context associated with potential for parental bias associated with the removal of colors and additives from a child's diet and stated "...the parents were not blind to the removal of additives/colors from their children's diets" and therefore expectancy bias could influence the parents expectations for foods with FCAs to produce more hyperactive behaviors. Because of the potential for such biases to be associated with parental observations, the view of the medical community is that parents are not in a position to make objective judgement for the identification of ADHD as they often lack a large enough reference group for comparison [7].

McCann, et al. [3] utilized a double-blinded test article protocol for their study and found that parents rated their children not exposed to FCAs to have decreased hyperactive behavior. Teachers in the study also rated children not exposed to FCAs to also have decreased hyperactive behavior compared to challenge periods in which the children were exposed to FCAs, but to a lesser degree than the parents. Additionally, the reported symptoms by parents as compared to teachers in the Southampton studies were less consistent (reflecting a higher degree of subjectivity) compared to reported symptoms by parents and teachers when effective interventions are tested (e.g. pharmacological treatment) [8]. In fact, the European Food Safety Authority (EFSA) re-analyzed the original data using a more appropriate and conventional statistical model. Using this model, where each subject served as its own reference, EFSA disagreed with two conclusions drawn by McCann, et al. [3] and the statistical significance of the findings. Overall, EFSA concluded: 1) The McCann, et al. [3] study provided limited evidence that the two mixtures of color additives and sodium benzoate had a small but statistically significant effect on behavior in a small number of children; 2) Those reported effects were not observed for all children in both age groups studied and were not consistent for the two mixtures of color additives; 3 ) That the study findings could not be extrapolated into an assessment of the these additives' impact on behavioral changes in the general population and 4) It was not possible to determine a potential sensitivity to individual additives [9].

In a replication of McCann's research, Lok, et al. [6] used a randomized, double-blind, placebo-controlled protocol including the increased doses of the color additives used in Mix A (FD \& C Yellow No. 6, FD \& C Yellow No. 5, carmoisine, and ponceau 4R) by McCann, et al. [3] in 8- to 9-year-old children in Hong Kong. In contrast to McCann, et al. [3], Lok, et al. [6] did not report observing an association between color additive intake and behavior. Lok was unable to produce the same findings of McCann, et al. [3] despite using the increased doses of the same color additives and a very similar study protocol. A follow-up call was conducted three months after the completion of the 6-week study in which it was reported that $52.5 \%$ of parents believed that additives did not affect their children's behavior, but $62.4 \%$ continued to follow an additive-free diet for their children. In contrast, $43.4 \%$ of parents believed that additives did affect their children's behavior, of which $20.5 \%$ observed a behavior change, $9.4 \%$ temper change, $6.8 \%$ mood change, $3.4 \%$ less hyperactive, and $2.6 \%$ attention change [6].

\section{Regulatory background}

Interest in the impact of food dyes and additives on behavior in children and adolescents continues to the present day. Additional research in this area has continued with varying levels of rigor and thus, often inconsistent results influence national policy on FCAs.

Beginning with the promotion and publication of epidemiological studies in the 1970's investigating potential links between consumption of color additives and behavioral effects in children, the US government initiated a number of formal reviews, the National Institute of Health 1982 and FDA 1986 and 2011, and communications on color additives with the latest effort beginning in October 2019 at the Science Board to the FDA [10]. The last formal review by the FDA occurred in the Food Advisory Committee (FAC) meeting convened in March 2011 to "...consider available relevant data on the possible association between consumption of certified color additives in food and hyperactivity in children, and to advise the US FDA as to what action, if any, is warranted to ensure consumer safety" [11]. The US FDA FAC determined that a causal relationship between exposure to color additives and hyperactivity in children in the general population has not been established. However, for certain susceptible children with ADHD and other problem behaviors, the data suggest that their condition may be exacerbated by exposure to a number of substances in food, including, but not limited to, synthetic FCAs. Findings from relevant clinical trials indicate that the effects on their behavior appear to be due to a unique intolerance to these substances and not to any inherent neurotoxic properties. The FAC also voted against recommending additional information to be disclosed on the product label of food containing certified color additives to ensure their safe use [12]. 
Citation: Llewellyn GC, Penberthy JK, Parker JM (2020) Food Color Additives in the US Food Supply: Review of Neurobehavioral Safety. J Pediatr Neurol Neurosci 4(1):55-72

In 2018, the California Legislature (SB-504 Synthetic food dyes) directed the California Environmental Protection Agency's Office of Environmental Health Hazard Assessment (OE$\mathrm{HHA}$ ) to address two questions related to color additives approved for use in foods by the United States Food and Drug Administration (FDA): 1) Do synthetic dyes adversely affect some children's behavior?; 2) If yes, what risk management options are available to the Legislature, if any? OEHHA subsequently requested information on nine FDA approved food color additives relating to possible neurologic and neurobehavioral impacts to be included in their risk assessment (OEHHA, 2018).

In addition to reviews performed by US government entities, other international expert food safety bodies, including EFSA and JECFA, have performed assessments that included an evaluation of the evidence associated with FCA and neurobehavioral endpoints. Each have not determined that restrictions on uses are not necessary based on the dataset evaluating a potential link between consumption or avoidance of food colors and neurobehavioral effects in children and adolescents [13]. However, the EU Parliament independent of the lack of concern following the EFSA assessments of the scientific evidence adopted into EU food labeling law requirement for the inclusion of additional label text, " may have an adverse effect on activity and attention in children" on products that contain the Southampton colors [14].

\section{Safety and regulatory status of FCAs}

Food additives including the FCAs must be demonstrated to be safe before they are allowed to be placed in foods and beverages. In the US, the FDA is charged as the public health agency to use science and scientific understanding to ensure that food additives, including color additives, are safe for their intended use. The seven FCAs included in this review (see Table 1) are FDA regulated as certified color additives [15]. While all color additives must undergo a pre-market safety assessment and approval, synthetic colors manufactured using petroleum-based starting materials are required to meet an additional layer of safety assurance by batch certification through analytical evaluation and approval by the FDA [16]. Records are available for each batch of color additive certified by the FDA [17]. In addition to their limited scope of regulatory approvals, Orange B and Citrus Red No. 2 are not included in this assessment because of their negligible contribution to human exposure. For this reason, they were not included in the FDA exposure assessment study published in 2016 that reported estimated intake of FD \& C color additives in the US population [18].

The seven FCAs included in this review (see Table 1) were re-reviewed more recently and determined safe for their intended use by the Joint FAO/WHO Expert Committee on Food Additives (JECFA) [19-22]. Similarly, the European Food Safety Authority (EFSA) has also reevaluated six of these seven color additives (FD \& C Green No. 3 is not used in Europe) among other non-US approved color additives which are approved for use in Europe. Both the JECFA and EFSA evaluations included the information from the Southampton studies evaluating neurobehavioral endpoints and determined that they continue to be considered safe for their intended use in foods [19-26].

\section{Attention-deficit/hyperactivity disorder}

In order to evaluate the potential for FCAs to induce or exacerbate ADHD symptoms in a child or adolescent, it is important to understand the state of knowledge associated with the conditions described as ADHD and their diagnosis. Between 2014 and 2016, approximately 10.6\% of children aged 5-17 years in the US were diagnosed with ADHD and understanding the cause(s) of behaviors in children is an active topic of scientific and medical research [27]. Presumably, there are far more youth who exhibit symptoms of ADHD but do not technically meet the full criteria for diagnosis of ADHD. The exact causes of ADHD are not fully understood but there is sufficient evidence that supports a multi factorial etiology involving genetic and environmental factors [28] and thus causative factors for symptoms of ADHD are likely to be complex.

The diagnosis of ADHD relies on qualitative behavioral assessment and there are currently no reliable biological markers that can be measured to diagnose ADHD, since selective and sensitive biomarkers pointing to an ADHD diagnosis have not been established [29]. This makes an accurate diagnosis of ADHD challenging. Complicating the ability for accurate diagnosis, numerous health-related issues not related to ADHD can present with similar symptoms as ADHD, including; hearing problems, learning or cognitive disabilities, sleep problems, depression or anxiety, and substance abuse [30]. Because other conditions or lifestyle behaviors can mimic ADHD symptoms, addressing such conditions and/or adopting lifestyle changes associated with better health may be impactful on the expression of ADHD and ADHD-like symptoms in children. The ability to determine the ADHD status of a child can also be complicated by differential scoring of a child's abilities in the evaluations included in the Diagnostic and Statistical Manual, DSM-5 [31] of mental disorders used for diagnosis of ADHD. The criteria, subtypes and terminology have also changed over the years, complicating things further. The term "Attention Deficit/Hyperactivity Disorder" was introduced in $D S M-I I I-R$, with the controversial elimination of Attention Deficit Disorder without Hyperactivity [32]. With the publication of the DSM- IV, the term ADHD was retained along with the introduction of three specific subtypes (predominantly Inattentive, predominantly Hyperactive-Impulsive, and Combined), defined by the presence of excessive symptoms of inattention and/or hyperactivity-impulsivity [33]. The release of DSM-5 is the latest update to ADHD nosology. The DSM-5 revisions include modifications to each of the ADHD diagnostic criteria (A-E), a terminological change in the ADHD subtype nosology, and the addition of two ADHD modifiers. Fair, et al. [34] evaluated the response ranges from DSM-IV, specified tests for children with and without an ADHD diagnosis and reported that the heterogeneity in the scoring of individuals with ADHD in the different tests fell within the range of individuals without an ADHD diagnosis on one or more specific tests. The lack of knowledge regarding causation and challenges in making diagnoses are formidable hurdles for accu- 
Citation: Llewellyn GC, Penberthy JK, Parker JM (2020) Food Color Additives in the US Food Supply: Review of Neurobehavioral Safety. J Pediatr Neurol Neurosci 4(1):55-72

rately understanding $A D H D$ and the factors that may impact these conditions.

The difficulty in an accurate ADHD diagnosis is well recognized and is a serious concern for specialists and advocates of children's health. This difficulty can be observed in the literature documenting the rate of over-diagnosis or misdiagnosis of ADHD in developed countries, including the US [35-40] According to the Centers for Disease Control and Prevention (CDC) [41], the estimated number of children diagnosed with ADHD in the US is 6.1 million based on a national 2016 parent survey. The absence of objective and consistent criteria for diagnosis calls ADHD studies into question since it compromises the validity of the response by introducing response misclassification. For example, concerns have been raised regarding over-diagnosis of ADHD in response to a recent study reporting suspiciously high prevalence rates up to $20 \%$ [42]. This is significantly higher than the CDC rate from 2016 and indicative of the challenges of accurately identifying base rates of the disorder.

According to recent publications, about one million children may be over- or misdiagnosed as having ADHD because their evaluation fails to address other factors that may explain their behavior [36]. There are compelling data showing that the age of the child relative to the age group against which the behavior is measured leads to misdiagnosis, and that boys are more than twice as likely to be diagnosed than girls $[35,36,39,40]$. Younger children are significantly more likely than their older peers in the same school grade to be diagnosed with ADHD and be prescribed with stimulants such as Ritalin, likely because their behaviors reflect more a measure of maturity than ADHD [40]. The diagnosis of ADHD is challenging and imprecise and this has ramifications on assessment of symptoms that may present considerable variability in response to treatment, and other environmental factors.

\section{Methods}

\section{Literature search strategy}

The objective of the literature search was to determine if newly published studies existed for evaluating the potential effects of FCA intake on ADHD symptoms in humans and to identify the latest review papers, including systematic reviews and meta-analyses. In order to obtain the evidence of an association between FCAs and hyperactive behaviors, nine literature searches were conducted utilizing the National Library of Medicine PubMed database to assess the published literature in this research area, two of which were conducted specifically on the effects of color additive intake on behavior in children and adolescents.

The first search regarding human research, conducted on 19 July 2019, addressed published literature associated with meta-analyses and literature reviews linking neurobehavioral or neurological effects with the intake of FCAs and used the following search terms:

(((Artificial food colors or artificial food dyes or artificial food coloring or artificial food colorant or food color additives or synthetic food colors or synthetic food dyes or synthetic food coloring)) AND (meta-analysis or literature review or systematic review)) AND (neurobehavioral or ADHD or children or attention deficit hyperactivity disorder). The first search returned 33 records.

A second search was conducted for the date range of January 01, 2017 (the month of the most current meta-analyses) [42] to 22 July 2019 (date of the search) intended to identify any human intervention or challenge studies associated with FCAs that were not captured in the literature reviews or meta-analyses. This search used the following search terms:

(((Artificial food colors or artificial food dyes or artificial food coloring or artificial food colorant or food color additives or synthetic food colors or synthetic food dyes or synthetic food coloring)) AND ("2017/01/01" [Date - Publication]: "3000" [Date - Publication])) AND (clinical study or intervention study or challenge study or clinical trial).

The second search returned 11 records.

Seven searches were performed intended to capture any neurobehavioral or neurotoxicity animal studies related to each FCA under review in this evaluation. Because safety research in animal models is typically specific to one compound, a literature search was performed for each FD \& C color rather than a generic FCA search. The date range started with the most recent EFSA evaluation because any available neurobehavioral or neurotoxicity study in animal models would have most likely been captured within their review. The search terms included (the name of the color or its synonyms) AND (neurobehavioral or neurotoxicity or non-clinical study or brain or nervous or learning or memory or cerebral). The specific search terms, criteria, and number of returned records for each search can be found in Table 2.

The seven searches returned a total of 559 references, though 159 records were duplicates.

\section{Inclusion and exclusion criteria}

The titles and abstracts, if applicable, of the returned records in all searches were then evaluated to determine their relevance for inclusion within this evaluation. The inclusion criteria were full-length articles in a peer reviewed journal; written in English; relevant to the respective search. Scientific discretion was used to determine if the titles, and abstracts, if available, were relevant given the search terms and objective of the search. These criteria led to the final selection of 12 manuscripts in the animal literature and 6 manuscripts in the human literature for further review. An additional three manuscripts in the animal literature, and two manuscripts in the human literature were identified via references from a returned record. The 23 key systematic reviews, meta-analyses, current clinical studies, and non-clinical studies identified from these searches are summarized in this review. A brief overview of the manuscripts on clinical and non-clinical research reviewed can be found in Table 3 and Table 4, respectively.

\section{Results}

\section{Human research review}


Citation: Llewellyn GC, Penberthy JK, Parker JM (2020) Food Color Additives in the US Food Supply: Review of Neurobehavioral Safety. J Pediatr Neurol Neurosci 4(1):55-72

Table 2: Summary of non-clinical literature searches on FCAs and behavior ${ }^{1}$.

\begin{tabular}{|c|c|c|c|c|c|}
\hline FD \& C Color Name & Synonyms & $\begin{array}{l}\text { Date of EFSA Opinion } \\
\text { adoption }\end{array}$ & $\begin{array}{l}\text { \# of records } \\
\text { returned }\end{array}$ & $\begin{array}{l}\text { \# of full-length } \\
\text { articles reviewed }\end{array}$ & $\begin{array}{l}\text { \# of relevant } \\
\text { unique records }\end{array}$ \\
\hline FD \& C Blue No. 1 & $\begin{array}{l}\text { Brilliant Blue FCF } \\
\text { CI Blue } 2 \\
\text { INS } 133 \\
\text { CAS RN 3844-45-9 }\end{array}$ & 07-Oct-10 & 229 & 7 & 4 \\
\hline FD \& C Blue No. 2 & $\begin{array}{l}\text { Indigo Carmine/Indigotine } \\
\text { CI Blue } 1 \\
\text { INS } 132 \\
\text { CAS RN 860-22-0 }\end{array}$ & 04-Jul-14 & 104 & 1 & 0 \\
\hline FD \& C Red No. 3 & $\begin{array}{l}\text { Erythrosine } \\
\text { INS } 127 \\
\text { CAS RN 16423-68-0 }\end{array}$ & 07-Oct-10 & 18 & 2 & $1,1^{*}$ \\
\hline FD \& C Red No. 40 & $\begin{array}{l}\text { Allura Red AC } \\
\text { CI Red } 17 \\
\text { INS } 129 \\
\text { CAS RN 25956-17-6 }\end{array}$ & 23-Sep-09 & 124 & 5 & $1,2^{* *}$ \\
\hline FD \& C Yellow No. 5 & $\begin{array}{l}\text { Tartrazine } \\
\text { CI Yellow } 4 \\
\text { INS } 102 \\
\text { CAS RN 1934-21-0 }\end{array}$ & 23-Sep-09 & 36 & 7 & 5 \\
\hline FD \& C Yellow No. 6 & $\begin{array}{l}\text { Sunset Yellow FCF } \\
\text { CI Yellow } 3 \\
\text { INS } 110 \\
\text { CAS RN 2783-94-0 }\end{array}$ & 24-Sep-09 & 25 & 4 & 0 \\
\hline FD \& C Green No. 3 & $\begin{array}{l}\text { Fast Green FCF } \\
\text { CI Food Green } 3 \\
\text { INS } 143 \\
\text { CAS RN 2353-45-9 }\end{array}$ & $N / A^{2}$ & 23 & 2 & 1 \\
\hline
\end{tabular}

${ }^{1}$ Each literature search was performed using the following formula: ((FD \& C Color name or Synonyms) AND (neurobehavioral or neurotoxicity or non-clinical study or brain or nervous or learning or memory or cerebral) using a date range from the date of EFSA Opinion Adoption to 26 July 2019 (i.e. date the searches were performed).

${ }^{2}$ No date filter was used for this literature search because EFSA has not published an Scientific Opinion on this color and JECFA's full safety monograph (FAS) is not available at the time of this writing.

*An additional publication [53] was identified via a reference in JECFA [55].

${ }^{* *}$ An additional two publications [54,77] were identified via a reference in Noorafshan, et al. [55].

Table 3: Review of clinical research between 2012- 2019.

\begin{tabular}{|l|l|l|l|}
\hline Authors (Year) & Methods/Design & Intervention Focus & Results/Conclusions \\
\hline Nigg, et al. [4] & $\begin{array}{l}\text { Quantitative meta-analysis to assess } \\
\text { the role of diet and of food colors in } \\
\text { ADHD or its symptoms. }\end{array}$ & FCAs & $\begin{array}{l}\text { Restriction diets reduced ADHD symptoms with an effect } \\
\text { size of g = 0.29 (95\% Cl, 0.07-0.53). Restriction diet } \\
\text { benefits some children with ADHD. Effects of food colors } \\
\text { were susceptible to publication bias or were derived from } \\
\text { small, nongeneralizable samples. }\end{array}$ \\
\hline $\begin{array}{l}\text { Stevens, et al. } \\
{[44]}\end{array}$ & $\begin{array}{l}\text { Examine research on mechanisms } \\
\text { by which FCAs may cause behavioral } \\
\text { changes in children with or without } \\
\text { ADHD }\end{array}$ & FCA challenge & $\begin{array}{l}\text { There are subgroups of children (with or without ADHD) } \\
\text { who react adversely to challenges with FCAs. The authors } \\
\text { review how early studies found few children who reacted } \\
\text { to challenges with 20-40 mg of FCAs. However, studies } \\
\text { using at least 50 mg of FCAs showed a greater percentage } \\
\text { of children who reacted to the challenge. }\end{array}$ \\
\hline
\end{tabular}


Citation: Llewellyn GC, Penberthy JK, Parker JM (2020) Food Color Additives in the US Food Supply: Review of Neurobehavioral Safety. J Pediatr Neurol Neurosci 4(1):55-72

\begin{tabular}{|c|c|c|c|}
\hline $\begin{array}{l}\text { Sonuga-Barke, } \\
\text { et al. [45] }\end{array}$ & $\begin{array}{l}\text { Meta-analyses of the efficacy of } \\
\text { dietary intervention (FCA elimination) } \\
\text { as a treatment for ADHD. }\end{array}$ & FCA eliminations & $\begin{array}{l}\text { All dietary (standardized mean differences }=0.21-0.48 \text { ) } \\
\text { and psychological (standardized mean differences }=0.40- \\
0.64 \text { ) treatments produced statistically significant effects } \\
\text { on ADHD behaviors. }\end{array}$ \\
\hline $\begin{array}{l}\text { Stevenson, et } \\
\text { al. [46] }\end{array}$ & $\begin{array}{l}\text { Review of studies of impact of dietary } \\
\text { treatments and FCAs on ADHD } \\
\text { symptoms }\end{array}$ & FCA elimination & $\begin{array}{l}\text { Average effect sizes for FCA elimination found ( } 0.18 \text { - } \\
0.42 \text { ). }\end{array}$ \\
\hline $\begin{array}{l}\text { HeilskovRytter, } \\
\text { et al. [47] }{ }^{¥}\end{array}$ & $\begin{array}{l}\text { Systematic review examining } \\
\text { association between FCA elimination } \\
\text { and ADHD symptoms in children. }\end{array}$ & FCA elimination & FCAs elimination not efficacious treatment for ADHD. \\
\hline $\begin{array}{l}\text { Catalá-López, } \\
\text { et al. [48] }{ }^{*}\end{array}$ & $\begin{array}{l}\text { Systematic review of pharmacological } \\
\text { and non-pharmacological treatments } \\
\text { of } A D H D\end{array}$ & FCA elimination & $\begin{array}{l}\text { FCA elimination not recommended as evidence-based } \\
\text { interventions using } 95 \% \mathrm{Cl} \text {, class effect size } 0.77 \text { ( } 0.23 \text { - } \\
\text { 2.64). }\end{array}$ \\
\hline $\begin{array}{l}\text { Feketea \& } \\
\text { Tsabouri [49] }\end{array}$ & $\begin{array}{l}\text { Review of FCAs on adverse/allergic } \\
\text { reactions }\end{array}$ & FCAs & $\begin{array}{l}\text { No effect sizes provided. Determined that adverse } \\
\text { reactions caused by FCAs are rare. }\end{array}$ \\
\hline $\begin{array}{l}\text { Pelsser, et al. } \\
\text { [42] }\end{array}$ & $\begin{array}{l}\text { Review of two meta-analyses of } \\
\text { double-blind placebo-controlled } \\
\text { trials evaluating the effect of FCA } \\
\text { elimination on children with ADHD }\end{array}$ & $\begin{array}{l}\text { FCA eliminations and } \\
\text { supplementation }\end{array}$ & $\begin{array}{l}\text { Determined no impact on behavior for supplementation. } \\
\text { For elimination of FCAs, effect sizes of impact on } \\
\text { behavior are } 0.44\left(95 \% \mathrm{Cl}: 0.16-0.72, \mathrm{I}^{2}=11 \%\right) \text { and } 0.21 \\
\left(95 \% \mathrm{Cl}:-0.02-0.43, \mathrm{I}^{2}=68 \%\right) \text { for parent ratings, } 0.08 \\
\left(95 \% \mathrm{Cl}:-0.07-0.24, \mathrm{I}^{2}=0 \%\right) \text { for teacher ratings, and } 0.11 \\
\left(95 \% \mathrm{Cl}:-0.13-0.34, \mathrm{I}^{2}=12 \%\right) \text { for observer ratings. }\end{array}$ \\
\hline
\end{tabular}

${ }^{\sharp}$ Literature identified via alternative means (e.g. listed as a reference within primarily literature results; identified in adjacent research)

Table 4: Review of the literature search results of animal studies.

\begin{tabular}{|c|c|c|}
\hline Author (Year) & Associated Colors & Study Design (Guideline \# if applicable) \\
\hline \multicolumn{3}{|c|}{ Literature involving a single FCA as the test article (opposed to mixtures of FCAs) } \\
\hline Alsalman, et al. [59] & FD \& C Yellow No. 5 & Experimental: Investigating toxicity of Yellow No. 5 in rat brain with high-doseasprin. \\
\hline Bhatt, et al. [58] & $\begin{array}{l}\text { Tartrazine } \\
\text { (FD \& D Yellow No. 5) }\end{array}$ & $\begin{array}{l}\text { Experimental: Screen the neurobiochemical effects of Tartrazine in rats after adminis- } \\
\text { tering the acceptable daily intakelevel }\end{array}$ \\
\hline El-Sakhawy, et al. [60] & $\begin{array}{l}\text { Tartrazine } \\
\text { (FD \& D Yellow No. 5) }\end{array}$ & $\begin{array}{l}\text { Experimental: Investigated the histological and immunohistochemical effect of Tartra- } \\
\text { zine on the cerebellum, submandibular glands, and kidneys of adult male albino rats }\end{array}$ \\
\hline Gao, et al. [56] & $\begin{array}{l}\text { Tartrazine } \\
\text { (FD \& D Yellow No. 5) }\end{array}$ & $\begin{array}{l}\text { Experimental: investigated the effect of Tartrazine on learning and memory functions in } \\
\text { mice and rats, examining the possible mechanisms involved }\end{array}$ \\
\hline Mohamed, et al. [57] & $\begin{array}{l}\text { Tartrazine } \\
\text { (FD \& D Yellow No. 5) }\end{array}$ & $\begin{array}{l}\text { Experimental: Investigated the protective effects of royal jelly and cod liver oil against } \\
\text { the possible neurotoxic impact of tartrazine on male rat pups brains }\end{array}$ \\
\hline Noorafshan, et al. [55] & $\begin{array}{l}\text { Allura Red } \\
\text { (FD \& C Red No 40) }\end{array}$ & $\begin{array}{l}\text { Experimental: Investigated the neuroprotective effect of Taurine against the possible } \\
\text { neurotoxic impact of Allura Red on rats' medial Prefrontal Cortex }\end{array}$ \\
\hline Tanaka, et al. [51] & $\begin{array}{l}\text { Brilliant Blue FCF } \\
\text { (FD \& C Blue No. 1) }\end{array}$ & $\begin{array}{l}\text { Experimental: Investigated the reproductive and neurobehavioral effects of Brilliant } \\
\text { Blue FCF in mice }\end{array}$ \\
\hline Yang, et al. [63] & $\begin{array}{l}\text { Fact Green FCF } \\
\text { (FD \& C Green No. 3) }\end{array}$ & $\begin{array}{l}\text { Experimental: Investigated Fast Green FCF's effect on lip polysaccharide-induced de- } \\
\text { pressive-like behavior and the underlying mechanisms }\end{array}$ \\
\hline Bawazir, et al. [54] ${ }^{*}$ & $\begin{array}{l}\text { Allura Red } \\
\text { (FD \& C Red No 40) }\end{array}$ & $\begin{array}{l}\text { Experimental: Investigated Allura Red's effect on neurotransmitter, antioxidant func- } \\
\text { tions, and bioelement contents of kidney, and brain tissues in male albino rats }\end{array}$ \\
\hline Dalal and Poddar $[53]^{*}$ & $\begin{array}{l}\text { Erythrosine } \\
\text { (FD \& C Red No. 3) }\end{array}$ & $\begin{array}{l}\text { Experimental: Investigated the role of brain regional serotonin metabolism including } \\
\text { its turnover, MAO-A activity, and plasma corticosterone status in relation to behavioral } \\
\text { disturbances due to Erythrosine }\end{array}$ \\
\hline \multicolumn{3}{|c|}{ Literature involving mixtures of FCAs as the test article } \\
\hline Ceyhan, et al. [78] & $\begin{array}{l}\text { FD \& C Blue No. } 1 \\
\text { FD \& C Red No. } 40 \\
\text { FD \& C Yellow No. } 6\end{array}$ & $\begin{array}{l}\text { Experimental: Investigated the effects of intrauterine exposure to a mixture of food } \\
\text { colors and additives (FCAAs) in rats on subunit concentrations of NMDARs and nAChRs } \\
\text { is forms }\end{array}$ \\
\hline Doguc, et al. [79] & $\begin{array}{l}\text { FD \& C Blue No. } 1 \\
\text { FD \& C Red No. } 40 \\
\text { FD \& C Yellow No. } 6\end{array}$ & $\begin{array}{l}\text { Experimental: Investigated the effects of maternally exposed FCAAs on cognitive perfor- } \\
\text { mance in rats }\end{array}$ \\
\hline
\end{tabular}


Citation: Llewellyn GC, Penberthy JK, Parker JM (2020) Food Color Additives in the US Food Supply: Review of Neurobehavioral Safety. J Pediatr Neurol Neurosci 4(1):55-72

\begin{tabular}{|l|l|l|}
\hline Doguc, et al. [80] & FD \& C Blue No. 1 & Experimental: Investigated the effects of maternally exposed FCAAs on neurobehaviour \\
& $\begin{array}{l}\text { FD \& C Blue No. } 2 \\
\text { and learning process in rat offspring }\end{array}$ \\
& $\begin{array}{l}\text { FD \& C Red No. } 3 \\
\text { FD \& C Red No. } 40\end{array}$ & \\
& $\begin{array}{l}\text { FD \& C Yellow No. } 5 \\
\text { FD \& C Yellow No. } 6\end{array}$ & \\
\hline Erickson, et al. [81] & FD \& C Red No. 3 & Experimental: Investigated the compounding effect of multigenerational prenatal stress \\
& FD \& C Red No. 40 & $\begin{array}{l}\text { and FCA consumption on the development of hyperactivity and anxiety-related behav- } \\
\text { iors across the lifespan in male rats. MPS treatment involved a family history of four } \\
\text { consecutive generations of prenatal stress }\end{array}$ \\
\hline & $\begin{array}{l}\text { FD \& C Yellow No. } 5 \\
\text { FD \& C Yellow No. } 6\end{array}$ & \\
\hline
\end{tabular}

FCAAs: food colors and additives

${ }^{\sharp}$ Literature identified as a relevant reference within one of the records retrieved from the literature search

FCAs and ADHD symptoms in children and adolescents: Our first task was to examine current research in human subjects on the relationship between the approved FCAs listed in Table 1 and behaviors associated with ADHD symptoms in children/adolescents. In the literature review of human studies, two types of study design approaches used for such clinical studies, challenge and interventional studies, were found. Challenge studies administer FCAs via food or beverages and examine the impact of such on behavior. Interventional studies involve removal of FCAs from the diets of children and adolescents and explore the impact on behavior.

This research was built upon by systematically exploring the meta-analyses and reviews of the research conducted in this area after 2012. As seen from Table 3, the number of review and meta-analysis manuscripts in this research area over the past 7-years is limited, and primarily review or implement meta-analyses on previous articles to assess the relationship between FCAs and intensity of ADHD symptoms in children and adolescents. The type and quality of reviews and analyses varies considerably and thus, findings must be interpreted with caution, as some reviews are general summaries of older studies and other analyses are sophisticated in their evaluation and summary of results.

Meta-analyses and Reviews in Humans from 2012-2019: Nigg, et al. [43] conducted a quantitative meta-analysis to assess the role of diet and intake of food colors on children's ADHD symptoms. The relevant literature for this meta-analysis included FCAs that are outside the scope of our evaluation (i.e. Orange B, Citrus Red \#2, Azorubine, Brown FX, Patent Blue $v$, and Brown HT). Evaluation of results from parent-generated reports yielded an effect size that did not survive correction for possible publication bias and was not reliable in studies confined to FDA-approved food colors. The entire set of teacher/observer reports yielded a non significant effect. However, when the authors evaluated a subset of the published studies, the teacher/observer reports demonstrated an effect that survived correction for possible publication bias. The authors estimated that $8 \%$ of children with ADHD may have symptoms related to consumption of synthetic food colors and that some children in the reviewed studies saw reduced symptoms of ADHD on restriction diets. However, this result was based solely on parental observational results and was not representative for studies that included child self-evaluation or evaluated FCAs alone as the test article. Lastly, the authors emphasize that despite the research over the past 20-years, there have been no studies exclusively evaluating FDA-approved FCAs. Because the results evaluated were susceptible to publication bias or were developed from data from small subsets of the dataset, the authors concluded that a scientifically supportable link between FCA consumption and ADHD symptoms did not support recommendations to remove FCAs from the diet and additional investigations are needed.

In a 2013 review, Stevens, et al. [44] examine the research on potential mechanisms by which FCAs and other food additives may cause behavioral changes in children with and without ADHD. It is noted that several of the FCAs and other test articles included within Stevens, et al. [44] fall outside of the scope of this review (i.e. carmoisine, Orange B, I-glutamic acid, sulfanilic acid, quinoline yellow, and aspartame). The authors focused only on research purporting that there are subgroups of children (with or without ADHD) who react adversely to challenges with FCAs. The authors noted differences in response percentages following exposures to higher amounts (>50 mg) than following exposures to lower amounts, $20-40 \mathrm{mg}$, and suggest that a need exists to identify a tolerable upper limit of exposures for children, including those at higher risk. Given that the authors could not identify concordance between the clinical and non-clinical datasets, they suggested that additional data will be needed that specifically investigates potential mechanisms that could be responsible for behavioral effects in small segments of children within both the general and ADHD diagnosed populations.

EUNETHYDIS, the European Network for Hyperkinetic Disorder, is a network of scientists and clinicians dedicated to the study and treatment of children with ADHD or hyper kinesis. The EUNETHYDIS European ADHD Guidelines Group published papers evaluating the data associating color additive intake and ADHD. In a publication on behalf of this group, Sonuga-Barke, et al. [45] identified eight papers that evaluated food color additives which met the authors' criteria for inclusion, of which four trials excluded certified food colors (i.e. excluded FCAs within scope of this review), two implemented Feingold-type diets, one excluded tartrazine, and one excluded unspecified food colors. The meta-analysis revealed a statistically significant, but weak, association between restric- 
tion of food color additives and behavior. However, when the analysis was limited to the four papers that utilized a protocol with low or no pharmacological interventions and to protocols that were blinded, the association between food color additives and behavioral effects was further reduced and ceased to be statistically significant. Overall, the evidence available to Sonuga-Barke, et al. [45] was insufficient to demonstrate a clear association between behavioral impact and food color additive intake, because the supporting evidence was limited to unblinded ratings made by parents, whom likely to have a biased interest in success of such interventions. The authors concluded that more evidence from blinded studies focusing on other facets of treating ADHD symptoms, such as behavioral interventions, neurofeedback, cognitive training, and restricted elimination diets, needs to be examined before FCA elimination can be supported as a treatment for core ADHD symptoms.

In a second publication on behalf of the EUNETHYDIS European ADHD Guidelines Group, Stevenson, et al. [46] focused on dietary treatments for ADHD symptoms and reviewed three meta-analyses related to ADHD and the purported efficacy of FCA elimination diet treatment $[42,43,45]$. Results indicated a small effect size when individual study results were converted to standardized mean difference (SMD) units for FCA elimination with an average of approximately 0.30 , ranging from $0.18-0.42$, which is likely to be lower, approximately 0.22 , when the highest quality studies are used. The generation of SMD is based on the magnitude of standard deviation difference that was found between the mean ADHD scores under the treatment and control conditions. This procedure is often used to measure effect size that is independent of the scales being used within the dataset. The authors concluded that "artificial food colour elimination is a potentially valuable treatment but its effect size remains uncertain, as does the type of child for whom it is likely to be efficacious" [46]. Agreeing with previous evaluations, the authors came to the same conclusion that the methodology used in most of the trials on which the meta-analyses are based was weak, limiting their ability to endorse FCA elimination or restriction as an efficacious treatment for ADHD.

Maren Johanne Heilskov Rytter, et al. [47] conducted a systematic review of literature evaluating the effects of FCA restriction diets on ADHD symptoms in two challenge studies, four elimination studies, and two studies that were considered both challenge and elimination studies. They evaluated whether children's symptoms worsened when exposed to FCAs. The authors noted that all of the studies evaluated were decades old and that the children included in those studies likely did not meet the criteria in place in 2015 for an ADHD diagnosis, which may be a common challenge to reviews of previous studies. The authors concluded that the studies reviewed had shortcomings and that although elimination diets may have promise in reducing ADHD symptoms, more thorough investigations are necessary to decide whether elimination diets are recommendable as part of treatment of ADHD symptoms.

In the systematic review of pharmacological and non-pharmacological treatments of ADHD, Catalá-López, et al. [48] also reported that dietary therapy, which included color additive restriction diet, lacked evidence as an effective treatment for reducing ADHD symptoms. This systematic review evaluated FCAs such as azo dyes but included several FCAs that are outside the scope of our evaluation as they are not approved for use in the US (i.e. carmoisine, quinoline yellow, and ponceau $4 \mathrm{R})$. The authors used a Bayesian random-effects model of analysis which allowed for an incorporation and modeling of the data from the publications selected and incorporated a comprehensive evaluation of the uncertainties from the data evaluated over a range of parameters rather than on a static basis as used in non-Bayesian models. The individual effect of treatment compared with placebo for the elimination diet was reported to be of very low quality $(0.77$; credibility interval 0.23-2.64). The authors concluded that dietary therapy (including FCA restricted elimination diet) cannot be recommended as evidence-based interventions for improving global functioning and reducing core ADHD symptoms until there is comparative efficacy from clinical trials.

Feketea and Tsabouri [49] examined the relationship between FCAs and adverse reactions. Their results showed that adverse reactions caused by FCAs are rare. The authors found that there is a 32-fold discrepancy between the perception of reactions by patients and parents and the reported adverse reactions to FCAs. The authors conclude that these discrepancies make it hard to identify whether or not FCAs actually trigger adverse reactions.

Pelsser, et al. [42] noted the inconsistency in the literature and conducted a review of two meta-analyses $[4,43]$ of double-blind placebo-controlled trials evaluating the effect of the artificial food color elimination on children with ADHD. The authors found SMD effect sizes for FCA elimination were higher as measured by parents (effect size $=0.21$ ), but lower when rated by teachers (effect size $=0.08$ ) and observers (effect size $=0.11$ ). The authors noted that effect sizes $\geq 0.2$ but $<0.5$ are considered to be small and also stated that further research is warranted with more stringent research design focussing on mechanisms of the potential for food and FCAs to produce effects on behavior.

Human clinical studies from 2017-2019: A second search was conducted for the date range of January 01, 2017 (the month of the most current meta-analysis) [42] to 22 July 2019 (date of the search) intended to identify any human intervention or challenge studies associated with FCAs that were not captured in the literature reviews or meta-analyses. This search returned 11 records, none of which met the inclusion criteria.

Clinical Study Protocols Specific to Evaluating FCAs and ADHD: An important aspect in obtaining the most useful and accurate data from clinical studies is to use a study protocol designed and optimized to evaluate the specific question at hand. In April 2009, the University of Massachusetts (UMass) Amherst Food Science Strategic Policy Alliance convened a meeting of experts, including food scientists, policy makers, pediatric nutritionists, psychologists, and biostatisticians to develop a model and methodology to assess potential links between color additives and ADHD in children [50]. Despite 
Citation: Llewellyn GC, Penberthy JK, Parker JM (2020) Food Color Additives in the US Food Supply: Review of Neurobehavioral Safety. J Pediatr Neurol Neurosci 4(1):55-72

the availability of such guidance since 2011, we were unable to find published research that utilized the methodology put forth by Kleinman, et al. [50].

\section{Animal research review}

Both EFSA and JECFA evaluated safety data associated with each color, including any available neurobehavioral or neurotoxicity studies in animal models. The dates of adopted EFSA Scientific Opinions were used as a starting point for the publication date filter of each literature search for each FCA. The results presented below summarize each EFSA Scientific Opinion, except for Fast Green FCF (FD \& C Green No.3) (because this color is not used in Europe and therefore no EFSA scientific opinion) and JECFA evaluation reports for all of the FCAs of interest, including Fast Green FCF (FD \& C Green No.3).

The seven literature searches regarding neurobehavioral or neurotoxicity animal studies returned a total of 559 records, 159 of which were duplicates, and 12 of which met the inclusion criteria (see Table 4). An additional two manuscripts were identified as a relevant reference within one of the records retrieved from the literature search (see Table 4).

FD \& C blue No. 1: Both EFSA and JEFCA have conducted recent safety evaluations for this color (synonym Brilliant Blue FCF) $[21,25]$ While several safety studies in animal models were considered in the both safety evaluations, none specifically measured neurobehavioral or neurotoxicity endpoints, and neither body identified a safety concern from the studies evaluated. The JECFA review included one additional study [51] that was published after the EFSA Opinion.

The most recent non-clinical study of Brilliant Blue FCF was conducted by Tanaka, et al. [51] who assessed neurobehavioral effects, including surface righting, inclined plane test, cliff avoidance, swimming behavior, olfactory orientation, exploratory behavior, Biel-type maze learning and spontaneous behavior in either or both $F_{0}$ and/or $F_{1}$ generations of $C D 1$ mice. The $F_{0}$ and $F_{1}$ generations were fed doses from $0.08,0.24$, and $0.72 \%$ of Brilliant Blue FCF in the diet, equaling doses up to $3855.5 \mathrm{mg} / \mathrm{kg}$ bw per day in the $F_{0}$ generation. In the $F_{0}$ generation, an assessment of exploratory behavior as measured by the number of horizontal activities in males was significantly $(p<0.05)$ increased only in the lowest dose group and an increasing trend was observed in females that did not reach statistical significance. Thus, no significant results were observed in females and a lack of dose responsiveness was observed in males for exploratory behavior. In females in the $F_{0}$ generation, movement time exhibited a significant tendency to be increased, and the average time of rearing exhibited a significant tendency to be decreased in the treatment. No other statistically significant effects were observed in the other behavioral tests in the $F_{0}$ generation. In the $F_{1}$ generation, measures of behavioral development were evaluated and sporadic and inconsistent statistically significant $(p<0.01$ or $p<0.05$ ) changes were observed in behavioral tests. The authors concluded that Brilliant Blue FCF was unlikely to produce effects in humans based on the sporadic observed changes in the neurobehavioral battery of test evaluated, the estimated intake levels in the Japanese population, and the poor absorption of Brilliant Blue FCF [51]. As part of its review of Tanaka, et al. [51], JECFA reported that the data were inconsistent and inadequate for use in a safety assessment [21].

FD \& C blue No. 2: Both EFSA and JEFCA have conducted recent safety evaluations for Indigo Carmine (FD \& C Blue No. 2) $[22,26]$. EFSA ANS adopted and published their scientific opinion on the re-evaluation of Indigo Carmine in 2014. While several safety studies in animal models were considered, none measured neurobehavioral or neurotoxicity endpoints and neither EFSA nor JECFA noted any safety concern from the studies evaluated, including sub acute, chronic, reproduction, and developmental toxicity studies. We did not identify any new studies specifically evaluating neurobehavioral endpoints for Indigo Carmine published after the 2014 EFSA evaluation. JECFA re-evaluated the safety of Indigotine (Indigo Carmine) during its $86^{\text {th }}$ Meeting [22], presumably using the same dataset as EFSA; however, the JECFA toxicological monograph has not become available to confirm if other studies were found and included. From their evaluation, EFSA and JECFA determined that the dataset available did not provide evidence that required a revision to the ADI and re-confirmed the previous ADI of $0-5 \mathrm{mg} / \mathrm{kg}$ bw per day. Both bodies concluded that dietary exposure to Indigotine was safe for all age groups, including children and adolescents.

FD \& C red No. 3: Erythrosine (FD \& C Red No. 3) was evaluated by EFSA in 2010 and JECFA in 2018 [22,51]. Both reviewed two studies in animal models measuring changes to neurobehavioral or neurobiochemical endpoints. The first was a dietary study conducted in mice over two generations, which demonstrated no adverse effects on reproductive endpoints but noted changes in several parameters of movement activity of exploratory behavior in the high-dose group only (adult $F_{0}$ and $F_{1}$ females and $F_{1}$ male offspring) [51,52]. The second study, reported by Dalal and Poddar [52,53], measured motor activity, neurochemical endpoints and histologic changes in rats following oral dosing from 1 to $200 \mathrm{mg} / \mathrm{kg} \mathrm{bw}$ per day $[23,53]$. While a dose-related decrease in motor activity and several neurochemical changes were noted at the doses equal to and greater than $10 \mathrm{mg} / \mathrm{kg}$ bw per day $(10,100$ and $200 \mathrm{mg} / \mathrm{kg}$ bw per day), these effects were transient and returned to normal levels within 7 hours post-dose.

While Tanaka, et al. [51] concluded that the observed changes in reproductive and neurobehavioral parameters in mice were adverse, EFSA and JECFA did not [22,52]. For the effects reported by Dalal and Poddar, EFSA and JECFA determined that results were inconsistent and not considered to be adverse [22,52]. Therefore, both expert bodies concluded that the two studies did not provide evidence that would indicate a need to revise the existing ADI $[22,52]$.

A second publication by Dalal and Poddar [53] that followed up testing on effects of Erythrosine on rat exploratory activity became available after EFSA had completed its literature evaluation. Similar to the earlier study, the authors reported increased rearing following exposure to 10 or $100 \mathrm{mg} /$ kg bw per day for 15 or 30 days, but not following exposure 
Citation: Llewellyn GC, Penberthy JK, Parker JM (2020) Food Color Additives in the US Food Supply: Review of Neurobehavioral Safety. J Pediatr Neurol Neurosci 4(1):55-72

of the lowest dose tested, $1 \mathrm{mg} / \mathrm{kg}$ bw per day. The authors investigated serotonin metabolism in various regions of the brain and reported elevated serotonin levels following exposure to Erythrosine. They hypothesized that a reduction in the clearance or an increase in synthesis of serotonin in the brain was initiated by exposure to Erythrosine.

This study was included in JECFA's re-evaluation of Erythrosine during its $86^{\text {th }}$ [22]. From its re-evaluation, JECFA concluded that the findings of the two publications were not applicable for risk assessment based on evidence indicating that Erythrosine does not penetrate the blood-brain barrier and that previous studies used higher doses of Erythrosine but did not observe behavioral changes.

FD \& C red No. 40: EFSA and JECFA re-evaluated Allura Red AC (FD \& C Red No. 40) $[20,23]$. EFSA reviewed one study in an animal model measuring changes to neurobehavioral or neurobiochemical endpoints. The study evaluated Allura Red $A C$ administered in the diet to mice over two generations. Few sporadic, non-dose-dependent effects were noted on reproductive endpoints, and few adverse effects were noted on movement activity and maze learning in F1 rats. The author concluded that such effects on reproduction or behavior are not expected to occur at typical human intake levels $[23,51]$. The ANS Panel came to a similar conclusion that the present database did not warrant any revision to the assessment or current ADI [23]. JECFA came to a conclusion similar to EFSA [23] that the available data do not give reason to revise the ADI [20]. The ADI of 0-7 mg/kg bw per day was re-confirmed, and JECFA concluded that dietary exposure to Allura Red AC was safe for all age groups, including children and adolescents.

Two studies were published after publication of the EFSA Scientific Opinion [23] and JECFA re-evaluation [20]. First, a study using male albino rats exposed ( $n=6$ per group) to 200 $\mathrm{mg} / \mathrm{kg}$ Allura Red by gavage for 8 weeks, reported reduced levels of brain neurotransmitters, serotonin, 5-hydroxyindoleacetic acid, gamma aminobutyric acid, and histamine and renal histological changes [54]. Additionally, Bawazir [54] reported reduced brain levels of antioxidant substrates malonaldehyde and glutathione peroxidase, leading to their hypothesis that oxidative damage induced by intestinal tract bacterial transformation following gavage exposure to $200 \mathrm{mg} / \mathrm{kg}$ bw per day Allura Red AC led to the observed neurological effects. While no data was presented, the author stated that measures of renal function, serum creatinine and urea, were statistically increased. The effects reported by Bawazir [54] from a gavage administration of $200 \mathrm{mg} / \mathrm{kg}$ bw/day dose of Allura Red AC were described to be statistically significant, but only reached a $p \leq 0.05$ value. The small number of rats in the two groups, and the use of single exposure amount likely impacted on the statistical power of the study. Additionally, the authors did not present historical control ranges for the endpoints evaluated. Based on the limitations of this report, its usefulness in risk assessment is considered low. While effects were reported as adverse, study design and reporting deficiencies significantly diminish the use of the data for assessing the safety of Allura Red (FD \& C Red No. 40).
The second study by Noorafshan, et al. [55] tested the oxidative effect hypothesis and reported structural changes in the medial prefrontal cortex of male Sprague-Dawley rats administered at either 7 or $70 \mathrm{mg} / \mathrm{kg}$ bw per day Allura RedAC by gavage for 6 weeks which could be mitigated with concomitant gavage exposure to $200 \mathrm{mg} / \mathrm{kg}$ bw per day of taurine. The changes reported in cortex volume were attributed to a reduction in the number of cells, neurons and glial cells, and diminished dendritic length. This led Noorafshan, et al. [55] to hypothesize that the protection observed from co-exposure to taurine could be a result of taurine's purported antioxidant, membrane stabilization, and calcium signaling properties. However, it is known that Allura Red AC is poorly absorbed into the systemic circulation from oral exposures $[20,23]$. Additionally, a number of lifetime/chronic toxicity and carcinogenicity studies in rats and mice using much larger numbers of animals per group ( $n=50-100$ ) have not demonstrated similar histological effects even though much higher levels of Allura Red AC (up to $7422 \mathrm{mg} / \mathrm{kg}$ bw/day) were administered via incorporation into feed [23].

Additionally, Noorafshan, et al. [55] evaluated the performance of rats exposed to Allura Red AC with and without co-exposure to taurine in two functional learning and memory assay types, novel objects recognition and the eight-arm radial maze tests. Noorafshan, et al. [55] reported a statistically significant $(p<0.05)$ decrease in total object exploration time in short- and long-term memory object recognition tests at the highest dose of Allura Red AC tested, $70 \mathrm{mg} / \mathrm{kg} \mathrm{bw}$ per day, administered by gavage, which was mitigated by co-exposure to taurine ( $200 \mathrm{mg} / \mathrm{kg}$ bw per day). Additionally, reductions $(p<0.05)$ in the preference index, a measure of visual novelty of objects, for short- and long-term memory were observed in mice exposed to the highest dose of Allura Red AC tested ( $70 \mathrm{mg} / \mathrm{kg}$ bw per day) and mitigated by the co-administration of taurine. Of note, unlike the observations reported from the novel objects recognition assay following gavage instillation of $70 \mathrm{mg} / \mathrm{kg}$ bw per day Allura Red AC, no statistically significant behavioral effects were observed following exposure to the acceptable daily dose (ADI) of $7 \mathrm{mg} / \mathrm{kg}$ bw per day [55]. In the eight-arm radial maze assay, Noorafshan, et al. [55] reported significant $(p<0.01)$ increases in working and reference memory errors at both exposure levels of Allura Red AC which were also diminished by co-exposure to taurine. Thus, Noorafshan, et al. [55] concluded that Allura Red AC may impair spatial learning and memory, as well as the number of glial cells at the current ADI $(7 \mathrm{mg} / \mathrm{kg}$ bw per day), however, simultaneous treatments with taurine and Allura Red AC may prevent these changes. The authors concluded that exposures of Allura Red 10x higher than the ADI could impair learning, memory, and mPFC structure, and, taurine may act as a neuroprotectant.

The findings of Bawazir [54] and Noorafshan, et al. [55] conflicted numerous studies that did not report any histological changes or overt neurological impairments with exposures of up to two orders of magnitude higher [23]. Taking the facts presented above into consideration, the effects reported by Bawazir [54] and Noorafshan, et al. [55] would not be expected to lead to a change in food safety organizations 
Citation: Llewellyn GC, Penberthy JK, Parker JM (2020) Food Color Additives in the US Food Supply: Review of Neurobehavioral Safety. J Pediatr Neurol Neurosci 4(1):55-72

changing their conclusion on the safety of Allura Red AC (FD \& C Red No. 40).

FD \& C yellow No. 5: EFSA and JECFA completed re-evaluations of Tartrazine (FD \& C Yellow No. 5) [20,24] EFSA reviewed two developmental neurobehavioral studies in mouse models. Both studies evaluated tartrazine administered in the diet to mice over one or two generations. No adverse effects on reproductive parameters were observed up to and including the highest dose levels ( 773 and $1225 \mathrm{mg} / \mathrm{kg}$ bw per day/ day for males and females, respectively). Neurobehavioral testing indicated some differences in performance of treated animals versus controls, often in the direction of improved, rather than decreased, performance following exposure to Tartrazine $[24,51]$. The findings were neither consistent nor dose-dependent, and the ANS Panel noted a lack of standardization of litter sizes which could have influenced the results and rendered interpretation of the studies difficult. EFSA concluded that these studies did not demonstrate any adverse effects of Tartrazine on neurobehavioral development and that revision of the ADI was not warranted based upon these studies. JECFA came to the same conclusions as EFSA on the data presented in Tanaka, et al. [24,51], indicating a lack of dose responsiveness and that the observed increases in activity were likely associated with increased body weight of the offspring at the time of evaluation.

After EFSA's Opinion was published in 2009, one paper evaluating neurobehavioral endpoints following exposure to tartrazine was published after the EFSA Opinion was released. Gao, et al. [56] reported differences in the results of neurobehavioral tests, including Morris water maze test ( $n=10$ mice per exposure group), step-through test ( $n=10$ mice per exposure group), and open-field test ( $n=10$ rats per exposure group), following 30 days of gavage exposure to $0,125,250$, or $500 \mathrm{mg} / \mathrm{kg}$ bw per day Tartrazine in Sprague-Dawley rats and $0,175,350$, or $700 \mathrm{mg} / \mathrm{kg}$ bw per day Tartrazine in Kun Ming mice. The authors reported significantly $(p<0.05$ and $p<0.01$ ) reduced learning and memory of mice in the stepthrough test at 350 and $700 \mathrm{mg} / \mathrm{kg}$ bw per day and increased open-field locomotor activity in rats at 250 and $500 \mathrm{mg} / \mathrm{kg}$ bw per day. The authors acknowledged that the doses tested were up to $>10 x$ of the then JECFA ADI when extrapolated to a human dose.

JECFA reviewed the results included in the Gao, et al. [56] paper and concluded that the number of animals per group ( $n=10$ ) was a too small to be of use in risk assessment. Following a review of the available data, JECFA increased its ADI from $0-7.5 \mathrm{mg} / \mathrm{kg}$ bw to $0-10 \mathrm{mg} / \mathrm{kg}$ bw and concluded that dietary exposure to Tartrazine was safe for all age groups, including children and adolescents [20].

We identified four additional studies investigating potential neurotoxicity of Tartrazine, i.e. Mohamed, et al., 2015; Bhatt, et al., 2018; Alsalman, et al., 2019; El-Sakhawy, et al., 2019 [57-60]. While these studies did not specifically evaluate behavioral endpoints, they did assess effects on brain cells and function following exposure to Tartrazine. Mohamed, et al. [57] administered by gavage $500 \mathrm{mg} / \mathrm{kg}$ bw of Tartrazine to Sprague-Dawley rats ( $n=6$ per group) either alone or in combination with cod liver oil or royal jelly. The authors reported Tartrazine induced decreases in brain neurotransmitter levels and in measures of antioxidant capacity (superoxide dismutase, catalase, and glutathione) increased malondialdehyde levels, and increased frequency of apoptotic brain cortex cells and concluded that Tartrazine, at levels much greater than the ADI, can impact neuronal cells of the brain which may or may not manifest into effects on behavior. The histological effects observed by Mohamed, et al. [57] were not noted as being observed in long term toxicity or carcinogenicity studies using mice, rats, and dogs at exposure levels more than 1.5 times greater with Tartrazine incorporated into the feed [23].

Bhatt, et al. [58] also reported similar changes in brain antioxidant enzymes as Mohamed, et al. [57] following gavage exposure to $7.5 \mathrm{mg} / \mathrm{kg}$ bw Tartrazine. The authors hypothesized that the changes observed were likely due to systemic exposure to metabolites of Tartrazine and concluded that a greater awareness of possible human health effects was warranted. As with the results reported by Mohamed, et al. [57], the reported effects by Bhatt, et al. [58] did not manifest into observed toxicity or carcinogenicity in long term studies using mice, rats, and dogs at exposure levels in multiple orders of magnitude greater with Tartrazine incorporated into the feed [23].

Alsalman, et al. [59] also reported on brain oxidative stress measures, and on the expression of a number of genes associated with antioxidant pathways in the brain of rats $(n=$ 6 per group). The study evaluated an exposure to Tartrazine at $700 \mathrm{mg} / \mathrm{kg}$ bw orally for up to 21 days and co-exposure to aspirin for various lengths of time. While the paper stated oral exposure to Tartrazine, one can presume based on the description of the exposure in $\mathrm{mg} / \mathrm{kg}$ bw that the administration was by gavage. The authors concluded that tartrazine is genotoxic and possibly tumorigenic in the brain. However, multiple long-term rodent studies utilizing feed incorporation of Tartrazine at exposures in excess of 2 orders of magnitude did not demonstrate an increased incidence carcinogenicity [23].

El-Sakhawy, et al. [60] evaluated Tartrazine in male albino rats ( $\mathrm{n}=10$ per group) by gavage at $7.5,15$, and $100 \mathrm{mg} / \mathrm{kg}$ bw for 30 days. The authors reported observing histological changes via light microscopy in the cerebellum, submandibular glands, and kidneys in all Tartrazine exposed groups. The authors also reported that through immune histological evaluation increased activity of the proteins proliferating cell nuclear antigen (PCNA) and glial fibrillar acidic protein (GFAP) in the cerebellum, submandibular glands, and kidneys in all Tartrazine exposed groups. Based on their findings, the authors suggested that Tartrazine could negatively impact the organs evaluated. However, multiple long-term rodent studies utilizing feed incorporation of Tartrazine at exposures in far exceeding the exposures in level and time frame did not demonstrate an increased incidence adverse effects in any organ evaluated [23].

The different methods of Tartrazine administration, gavage versus incorporation in feed, have shown marked dif- 
Citation: Llewellyn GC, Penberthy JK, Parker JM (2020) Food Color Additives in the US Food Supply: Review of Neurobehavioral Safety. J Pediatr Neurol Neurosci 4(1):55-72

ferences in reported effects in the literature. Tartrazine absorption, distribution, metabolism and excretion have been well studied in laboratory animals and humans. When administered orally, absorption of Tartrazine is low $(<5 \%)$ with most of the absorbed Tartrazine excreted unchanged in urine [23]. However, Tartrazine undergoes extensive metabolism by gastrointestinal micro flora to sulphanilic acid and aminopyrazolone whichare more readily absorbed than Tartrazine [23] and thus may have a greater potential for higher systemic exposure. Additionally, the results reported by Mohamed, et al. [57], Bhatt, et al. [9], Alsalman, et al. [59] and El-Sakhawy, et al. [60] were all observed following a bolus exposure through gavage administration. The long term toxicity and carcinogenicity studies that utilized Tartrazine administration through incorporation in the feed did not report adverse findings associated with the organs evaluated Mohamed, et al. [57]; Bhatt, et al. [58]; Alsalman, et al. [59]; El-Sakhawy, et al. [60] even though the total delivered exposure was much larger, up to 2 orders of magnitude [23]. While studies using gavage exposures have reported observing Tartrazine-induced effects deemed to be adverse, food safety evaluations will generally place greater weight and consideration on studies that utilized properly controlled and evaluated feed exposures as these better resemble human exposure.

FD \& C yellow No. 6: EFSA and JECFA re-evaluated Sunset Yellow FCF (FD \& C Yellow No. 6) [19,23]. EFSA reviewed one developmental neurobehavioral study in an animal model $[23,51]$. This study evaluated Sunset Yellow FCF administered in the diet to mice over two generations. No adverse effects were observed in the $\mathrm{F}_{0}$ generation up to and including the highest dose level $(0.05 \%, 0.15 \%$, and $0.45 \%$, corresponding to approximately 83,259 , and $773 \mathrm{mg} / \mathrm{kg}$ bw per day). In the $\mathrm{F}_{1}$ generation, there were a few statistically significant differences from controls during the lactation phase, but these effects were transient and non-dosedependent. Neurobehavioral testing indicated a dose-dependent effect on functional development in only one of five tests (swimming direction), in only one sex (females) and detected during only one of two examination periods (Postnatal Day 4). Effects noted on other parameters of neurobehavioral development were sporadic, not consistent and not dosedependent. Evaluation of the $F_{1}$ offspring for performance in a water T-maze demonstrated some differences, which were not consistent, dose-related, or entirely adverse, leading the author to conclude that any differences noted might not have been caused by Sunset Yellow FCF, a conclusion reiterated by EFSA, which stated that the study did not demonstrate an adverse effect of Sunset Yellow FCF on reproductive parameters or physical or behavior development of offspring of treated parental generations. EFSA set the NOAEL for this study as the highest dose tested, i.e. $0.45 \%$, corresponding to approximately $773 \mathrm{mg} / \mathrm{kg}$ bw per day. Based upon uncertainties and treatment-related effects defined in other toxicological studies in the Sunset Yellow FCF database, EFSA decided to temporarily reduce the ADI from 2.5 to $1.0 \mathrm{mg} / \mathrm{kg}$ bw per day [23]. Based on receipt of additional data, EFSA has since revised the ADI of Sunset Yellow to $4 \mathrm{mg} / \mathrm{kg}$ bw per day [60].

JECFA came to a similar conclusion as EFSA [23] indicating that dietary exposure to Sunset Yellow FCF was safe for all age groups, including children and adolescents. In its evaluation of the evidence, JECFA relied upon data from long term exposure studies toxicity studies from in its decision to increase the ADI from 2.5 to $4 \mathrm{mg} / \mathrm{kg}$ bw/day matching the revised $A D I$ developed by EFSA $[19,61]$.

FD \& C green No. 3: In 2017, JECFA reported on its re-evaluation of the safety data associated with Fast Green FCF (FD \& C Green No. 3) and re-affirmed an ADI up to $25 \mathrm{mg} / \mathrm{kg}$ bw per day based on a NOAEL of $2500 \mathrm{mg} / \mathrm{kg}$ bw per day observed in a rat carcinogenicity study. JECFA also concluded that dietary exposure to Fast Green FCF was safe for all age groups, including children and adolescents. In its evaluation, JECFA noted published studies demonstrating the potential for Fast Green FCF to interact with the purinergic $P 2$ receptor membrane channel protein pannexin 1 in constructed Xenopus oocyte expression models [21], but indicated that further work would be needed to determine if the model system has any relevance to food safety [21]. Additionally, it is known that Fast Green FCF does not cross the blood-brain barrier indicating that such modeling is not representative of the in vivo situation following ingestion of Fast Green FCF [62].

In ICR mice, Yang, et al. [63] reported that an intraperitoneal (i.p.) injection of $100 \mathrm{mg} / \mathrm{kg}$ bw per day of Fast Green FCF for seven days mitigated lipopolysaccharide-induced depressive effects on a number of functional behavioral endpoints, forced swim test, sucrose preference test, and novelty-suppressed feeding test, without itself producing effects on these endpoints [63]. Based on the i.p. route of administration, the findings of this study are not relevant to a food safety assessment as data from oral exposure studies and an understanding of systemic exposure exists.

\section{Conclusion}

The literature on human studies from the past decade does not offer a strong, plausible, or reliable explanation that FCAs present in or eliminated from the diet has an impact on ADHD symptoms in children and adolescents. There is a lack of clinical research exclusively on individual FD \& C colors. Instead, the studies in humans evaluated mixtures of FCAs or mixtures of FCAs along with other food additives rather than single FCAs individually and many were done including colors not approved for use in the US. While this approach may be a good representation of "real world" exposure scenarios for the combination of only certain FCAs needed to produce the desired color, this approach significantly impacts the ability to evaluate the safety of individual FCAs and does not replicate the vast majority of "real-world" ingestion scenarios for mixtures of FCAs. Additionally, studies frequently feature subjective ratings only and often include biased results based on parent, teacher, or other outside interpretation of behavior. The actual subjects' (children with or without ADHD) ratings of behavior are often not objective, but rather subjectively recorded or measured, and behavioral ratings and tests are almost never utilized. Many studies used outdated criteria for diagnosis of $A D H D$, or do not include any information about diagnostic evaluations or status. Additionally, FCA elimination studies did not demonstrate efficacy as compared to pharma- 
Citation: Llewellyn GC, Penberthy JK, Parker JM (2020) Food Color Additives in the US Food Supply: Review of Neurobehavioral Safety. J Pediatr Neurol Neurosci 4(1):55-72

cological interventions. Because the evidence indicates that the effects of dietary elimination strategies as reported from clinical studies are of limited efficacy, the elimination of any one component of the diet is likely not a viable treatment for $A D H D$ and does not account for the multifactorial foundation of this disease, which is complex yet widely accepted as primarily genetic. Kanarek [64] reviewed the history of FCAs and increased hyperactivity in children with ADHD. The author reports that in the early 1970s, Dr. Feingold found that when hyperactive children were given a diet free of FCAs, symptoms of hyperactivity were reduced. More rigorous empirical studies over the next 20-years were less supportive of this finding. Kanarek [64] further describes how the British government requested that food manufacturers remove most FCA from their products in 2009 presumably in response to more recent research and public petitions. Despite the British government's request for the removal of FCAs, Kanarek concluded that "while these strictures could have positive effects on behavior, the removal of food dyes is not a panacea for ADHD, which is a multifaceted disorder with both biological and environmental underpinnings," [64].

Non-clinical data associated with functional neurobehavioral measures following exposure to the FCAs subject to this review have been published. Some of this evidence has been reviewed by expert food safety organizations such as EFSA and JECFA as part of their safety evaluations for the use of these FCAs in foods. The functional neurobehavioral data reported for individual FCAs and mixtures of FCAs have a number of similarities. These similarities include that the magnitude of changes observed have been small, inconsistent, and not dose-responsive in nature. Because of the limitations associated with the current dataset, such functional neurobehavioral data have not affected safety conclusions nor warranted revisions to ADIs by expert food safety organizations. Additionally, newly developed efforts, such as the National Toxicology Program's focus on evaluating developmental neurtotoxicitypotential of compounds or chemicals of interest have not included aspects of clinical behavioral assessment, but rather focused on additional non-clinical models [65].

Another aspect to consider for the incorporation of non-clinical neurobehavioral data into assessments of the safety of FCAs is that the current non-clinical models do not specifically provide direct correlation to human ADHD. Because $A D H D$ is heterogeneous and the neurobiological understanding of ADHD is lacking in humans, the current non-clinical behavioral models may be models of "ADHD-like" symptoms [66]. Also, much of the available non-clinical functional neurobehavioral data for FCAs concluded that effects were observed on working memory. Effects on working memory in non-clinical, rodent models, are likely not applicable to understanding the potential to produce ADHD in humans following exposure to a substance. Publications reporting clinical differences between deficits in working memory and ADHD have demonstrated that while impact on working memory can be a part of $A D H D$, improvement of working memory deficit has limited effect on the clinical manifestation of ADHD $[67,68]$.

While this manuscript was in preparation, a new publica- tion was identified that reported on findings from a pilot clinical study evaluating exposure to FCAs and effects on college students was identified. The study evaluated the effect of FCAs on ADHD symptoms and electroencephalography (EED) in a small number of college students with $(n=18)$ and without $(n=11)$ diagnosed ADHD [69]. Each group avoided FCAs in their diet for two weeks prior to evaluation and during the 2-week evaluation period. The double-blinded study utilized a crossover challenge with 3 exposures to $225 \mathrm{mg}$ of a mixture of Red No. 40, Red No. 3, Yellow No. 5, Yellow No. 6, Blue No. 1, Blue No. 2 or no AFCs added to chocolate cookies. Cookies were consumed for 3 consecutive days with testing occurring on the third day of each week of the trial. Prior to the initiation of the study, all participants completed the Adult ADHD Self-Report Scale (ASRS), a mix of simple and complex attention measures, and a baseline EEG. Additionally, the diagnosed ADHD group was asked to refrain from taking ADHD medications during the study period.

The authors reported finding no differences in the measures of attention in the ADHD diagnosed and control groups following intake of both AFC-containing and placebo cookies. The baseline EEG recordings were consistent with previous studies and demonstrated no differences between groups. Differences in the ADHD group were demonstrated in both mean gamma power and relative alpha power in the posterior region with EEG when eyes were closed, and the mean posterior gamma was increased during the AFC condition relative to placebo. The authors noted that gamma power is not widely reported in the ADHD literature, and they identified one other study in adults which did not produce the same results. While such EEG changes have been noted in the literature, The American Academy of Neurology (AAN) published assessed quantitative EEG as a diagnostic tool for ADHD and determined that such testing is not ready for routine clinical use [70]. Additionally, Kirkland, et al. [69] noted that their findings were not conclusive and that more study would be necessary to determine if their EEG findings were meaningful. The AAN assessment noted that the data set is inconclusive for ADHD diagnosis using EEG measures and changes in EEG measurements are also observed with other diagnoses. Based on the findings presented by Kirkland, et al. [69] and the guidance provided by the AAN, our conclusions are not impacted by this latest publication.

\section{Limitations and recommendations}

Limitations of this review: This review has several limitations. First, the complexity of ADHD evaluation, lack of knowledge associated with risk factors for ADHD, inconsistent clinical study protocols, and extrapolation of the results from non-clinical data to humans are challenges in interpreting the dataset. Secondly, the enormity and complexity of the literature set associated with FCAs and neurobehavioral measures could complicate the ability of the chosen literature search strategy to extract all of the references that provide interpretations of potential effects of FCAs. Thirdly, this work did not follow meta-analysis or Systematic Review protocols. The work was designed and intended to gather the existing clinical and non-clinical evidence associated with FCAs and provide 
a critical evaluation of said scientific evidence. By gathering and evaluating the totality of the evidence, conclusions can be drawn that demonstrate how the weight of the scientific evidence can be interpreted. Additionally, future publications of new data may impact the conclusions that we have drawn from the current dataset.

Limitations of current literature: Because food intake is a requirement for all humans, understanding the strengths and limitations of clinical research is an important factor when evaluating foods, food ingredients, and food additives, including color additives, for safety. Thus, we must critically examine the research and adequately identify the limitations of such. There are several limitations to the research reviewed herein and thus, to the conclusions that can be drawn from it. Some limitations include the nature and kind of studies examined, as well as the multi-factorial nature of ADHD and ADHD symptoms and limitations on our current knowledge regarding the etiology of ADHD symptoms.

The research to date on FCAs and their relationship to ADHD symptoms is fairly sparse, lacks rigor and standardization, is inconsistent and thus, it is challenging to draw meaningful conclusions from the data. We know that there are limitations in all human subject research due to biases. This bias can begin with the recruitment of study subjects that may not represent the population through self-selection of participation [71] and extends to subjective judgements in interpretation of effects) [72]. The value of objective measures of effect is critical for evaluating behavioral responses, especially in ADHD. Emser, et al. [73] concluded that objective measures provide better prevention of bias from an evaluator in the detection of a response and other errors associated with subjective measures for ADHD. As noted in other published reviews of the available data, several of the studies reviewed suffer from various sources of bias such as raters may have been unblinded in portions of protocols to assess behavior change and thus results should be viewed with this in mind.

We also explored systematic reviews in the literature in order to evaluate findings in the recent years. The systematic review approach is a common practice and often evaluates publications covering the same topic but may evaluate less compelling or rigorous studies [74]. The ability of a systematic review to be a valuable and reliable tool may be affected by bias inherent to the design, conduct, analysis, or reporting in the studies that it evaluates [75]. In the conduct of a systematic review, the extent by which biases have impacted the author conclusions may be difficult to know [76], thus any application of these conclusions must be interpreted with caution. In addition, papers that provide a frank discussion on their own limitations may be seen to be less effected by biases.

An additional significant concern is the fact that the etiology and course of ADHD is multi-factorial and not fully understood. Thus, determining what may or may not produce symptoms or worsen symptoms over time is very challenging, and may include social, familial, and personal influences as well as genetic and biological components.

Presumably, any ingested compound, such as food items and FCAs used in such, may contribute only as fraction of causal factors driving behavior and report of such behavior. Study design can be modified to address these concerns and would include using blinded raters who are not related to or intimately involved in a relationship with the research study participants. Having parents and teachers as raters is handy for research on children and adolescents but is not the most rigorous design for evaluating objective changes in behavior. We advocate for the use of standardized behavioral ratings from trained professionals and the use of standardized behavioral assessments administered via computer. Future research will benefit from increasing awareness of the biases inherent in RCTs and strive to address them and possibly utilize protocols specifically developed to address the question of potential behavioral effects induced by FCAs. Also, additional knowledge of the causes, diagnosis, course, and management of ADHD must also be expanded in order for objective and clinically relevant conclusions to be drawn about the impact of FCAs on ADHD symptoms and behaviors.

Our review of the research literature on the available elimination or induction studies indicates that evidence does not exist that provides adequate scientific support to link FCAs consumption to increasing ADHD symptoms in humans. We propose that additional rigorous research, possibly using methodology put forth by Kleinman, et al. [50], will be required to appropriately evaluate the impact of FCAs on behavior in children diagnosed with ADHD or children with symptoms of ADHD. Future research must address the limitations noted in the previous research in order to contribute to the literature in an objective and clinically relevant manner.

Additionally, further research is needed to assess the impact and role of pharmacological (stimulants, non-stimulants, antidepressants, antipsychotics, and other drugs), psychological (behavioral, cognitive training and neurofeedback), and alternative medicine (dietary therapy, fatty acids, amino acids, minerals, herbal therapy, homeopathy, and physical activity) on ADHD and ADHD symptoms in children [48]. Research on multimodal or combined (i.e. pharmacological, psychological, and alternative medicine) therapies to produce benefits in various facets of ADHD at once is also needed.

\section{Acknowledgement}

The funding sponsor of this research is the International Association of Color Manufacturers (IACM). Authors Llewellyn and Parker are employed by Toxicology Regulatory Services, Inc. (TRS), consultants to IACM, the research sponsor. Author Penberthy is employed by the University of Virginia School of Medicine and received funding from IACM for her contribution to this manuscript. IACM reviewed the draft manuscript, however, the manuscript authors were not required to accept sponsor comments.

\section{References}

1. Burrows JDA (2009) palette of our palates: A brief history of food coloring and its regulation. Comprehensive Reviews in Food Science and Food Safety 8: 394-408.

2. Feingold BF (1975) Hyperkinesis and learning disabilities linked to artificial food flavors and colors. Am J Nurs 75: 797-803. 
Citation: Llewellyn GC, Penberthy JK, Parker JM (2020) Food Color Additives in the US Food Supply: Review of Neurobehavioral Safety. J Pediatr Neurol Neurosci 4(1):55-72

3. McCann D, Barrett A, Cooper C, et al. (2007) Food additives and hyperactive behavior in 3-year-old and $8 / 9$ year-old children in the community a randomized, double-blinded, placebo controlled trial. The Lancet 370: 1560-1567.

4. Schab DW, Trinh NH (2004) Do artificial food colors promote hyperactivity in children with hyperactive syndromes? A meta-analysis of double-blind placebo-controlled trials. J Dev Behav Pediatr 25: 423-434.

5. Bateman B, Warner JO, Hutchinson E, et al. (2004) The effects of a double blind, placebo controlled, artificial food colourings and benzoate preservative challenge on hyperactivity in a general population sample of preschool children. Arch Dis Child 89: 506-511.

6. Lok KYW, Chan RSM, Lee VWY, et al. (2013) Food additives and behavior in 8- to 9-year-old children in Hong Kong: A randomized, double-blind, placebo-controlled trial. J Dev Behav Pediatr 34: 642-650.

7. Ougrin D, Chatterton S, Banarsee R (2010) Attention deficit hyperactivity disorder (ADHD): Review for primary care clinicians. London J Prim Care 3: 45-51.

8. Schachter HA, Pham B, King J, et al. (2001) How efficacious and safe is short-acting methylphenidate for the treatment of attention-deficit disorder in children and adolescents? A meta-analysis. CMAJ 165: 1475-1488.

9. https://efsa.onlinelibrary.wiley.com/doi/pdf/10.2903/j. efsa. 2008.660

10. https://www.fda.gov/media/135001/download

11. FDA (United States Food and Drug Administration) (2018b) Center for food safety and applied nutrition, food advisory committee meeting (March 30-31, 2011), certified color additives and childhood hyperactivity, charge and questions.

12. https://wayback.archiveit.org/org1137/20170406211705/ https://www.fda.gov/downloads/AdvisoryCommittees/ CommitteesMeeting Materials/FoodAdvisoryCommittee/ UCM255119.pdf

13. Lehto S, Maria B, Alexandra K, et al. (2016) Comparison of food colour regulations in the EU and the US: A Review of current provisions. Food Additives and Contaminants: Part A 34: 335-355.

14. http://www.europarl.europa.eu/sides/getDoc.do?language $=E N \&$ type $=$ IM-PRESS\&reference $=20080707$ IPR33563

15. https://www.fda.gov/Food/IngredientsPackagingLabeling/FoodAdditivesIngredients/ucm094211.htm\#qacolor

16. https://www.fda.gov/forindustry/coloradditives/colorcertification/default.htm

17. https://www.fda.gov/ForIndustry/ColorAdditives/ColorCertification/ColorCertificationReports/ucm2005520.htm

18. Doell DL, Folmer DE, Lee HS, et al. (2016) Exposure estimate for FD\&C colour additives for the US population. Food Addit Contam Part A Chem Anal Control Expo Risk Assess 33: 782-797.

19. https://apps.who.int/iris/bitstream/handle/10665/44788/ WHO_TRS_966_eng.pdf;jsessionid=C52AAF9B899475DB4E$0876 \bar{B} 1$ E7CFCCD5 ? sequence $=1 \#$ page $=58$

20. http://apps.who.int/iris/bitstream/handle/10665/250277/9789 241210003-eng.pdf?sequence $=1$

21. ht t p: // a p ps.who.int/iris/bitstream/han dle $/ 10665 / 259483 / 9789241210164$ eng.pdf;jsessionid=9ACOD8A17E434AB528210C95CB75752E? sequence $=1$
22. http://www.who.int/foodsafety/areas_work/chemical-risks/ JECFA86-Summary.pdf?ua=1

23. https://efsa.onlinelibrary.wiley.com/doi/epdf/10.2903/j. efsa.2009.1327

24. https://efsa.onlinelibrary.wiley.com/doi/epdf/10.2903/j. efsa.2009.1331

25. https://efsa.onlinelibrary.wiley.com/doi/epdf/10.2903/j. efsa.2010.1853

26. https://efsa.onlinelibrary.wiley.com/doi/epdf/10.2903/j. efsa.2014.3768

27. https://www.cdc.gov/nchs/data/hus/hus17.pdf

28. https://www.aacap.org/AACAP/Families_and_Youth/Resource_ Centers/ADHD_Resource_Center/FAQ.aspx\#question7

29. Hamed Alaa M, Aaron J Kauer, Hanna E Stevens (2015) Why the Diagnosis of Attention Deficit Hyperactivity Disorder Matters. Front Psychiatry 6: 168.

30. https://www.health.harvard.edu/blog/5-common-problemsthat-can-mimic-adhd-2018010913065

31. APA (American Psychiatric Association) (2013) DSM (Diagnostic and statistical manual of mental disorders (DSM-5).

32. APA (American Psychiatric Association) (1987) DSM (Diagnostic and statistical manual of mental disorders (DSM-III-R).

33. APA (American Psychiatric Association) (1994) DSM (Diagnostic and statistical manual of mental disorders (DSM-IV).

34. Fair DA, Bathula D, Nikolas MA, Nigg JT (2012) Distinct neuropsychological subgroups in typically developing youth inform heterogeneity in children with ADHD. Proc Natl Acad Sci USA 109: 6769-6774.

35. Evans WN, Melinda S Morrill, Stephen T Parente (2010) Measuring inappropriate medical diagnosis and treatment in survey data: The case of ADHD among school-age children. Journal of Health Economics 29: 657-673.

36. Elder Todd E (2010) The importance of relative standards in ADHD diagnoses: Evidence based on exact birth dates. Journal of Health Economics 29: 641-656.

37. Bruchmüller K, Jürgen Margraf, Silvia Schneider (2012) Is ADHD diagnosed in accord with diagnostic criteria? Overdiagnosis and influence of client gender on diagnosis. J Consult Clin Psychol 80: 128-138.

38. Ford-Jones Polly Christine (2015) Misdiagnosis of attention deficit hyperactivity disorder: Normal behaviour and relative maturity. Paediatrics \& Child Health 20: 200-202.

39. Eva Charlotte Merten, Jan Christopher Cwik, Jürgen Margraf, et al. (2017) Overdiagnosis of mental disorders in children and adolescents (in developed countries). Child Adolesc Psychiatry Ment Health 11: 5.

40. Layton TJ, Barnett ML, Hicks, et al. (2019) Attention deficit-hyperactivity disorder and month of school enrollment. $\mathrm{N}$ Engl J Med 379: 2122-2130.

41. Danielson M, Rebecca H Bitsko, Reem M Ghandour, et al. (2018) Prevalence of parent-reported ADHD Diagnosis and Associated Treatment Among U.S. Children and Adolescents, 2016. J Clin Child Adolesc Psychol 47: 199-212.

42. Pelsser LM, Frankena K, Toorman, et al. (2017) Diet and ADHD, reviewing the evidence: $A$ systematice review of meta-analyses 
Citation: Llewellyn GC, Penberthy JK, Parker JM (2020) Food Color Additives in the US Food Supply: Review of Neurobehavioral Safety. J Pediatr Neurol Neurosci 4(1):55-72

of double-blind placebo controlled trials evaluating the efficacy of diet interventions on the behavior of children with ADHD, PLOS.

43. Nigg, Lewis, Edinger, et al. (2012) Meta-analysis of attention-deficit/hyperactivity disorder or attention-deficit/hyperactivity disorder symptoms, restriction diet, and synthetic food colors. J Am Acad Child Adolesc Psychiatry 51: 86-97.

44. Stevens L, Kuczek T, Burgess JR, et al. (2013) Mechanisms of behavioral, atopic, and other reactions to artificial food colors in children. Nutr Rev 71: 268-281.

45. Sonuga-Barke EJS, Brandeis D, Cortese, et al. (2013) Nonpharmacological interventions for ADHD: Systematic Review and meta-analysis of randomized control trials of dietary and psychological treatments. Am J Psychiatry 170: 275-289.

46. Stevenson J, Buitelaar J, Cortese S, et al. (2014) Research Review: The role of diet in the treatment of attention-deficit/hyperactivity disorder-an appraisal of the evidence on efficacy and recommendations on the design of future studies. Journal of Child Psycology and Psychiatry. 55: 416-427.

47. Maren Johanne Heilskov Rytter, Louise Belt oft Borup Andersen, Tine Houmann, et al. (2015) Diet in the treatment of ADHD in children-A systematic review of the literature. Nord J Psychiatry 69: 1-18.

48. Catalá-López F, Hutton, Núñez-Beltrán, et al. (2017) The pharmacological and non-pharmacological treatment of attention deficit hyperactivity disorder in children and adolescents: A systematic review with network meta-analyses of randomised trials. PLOS One 12: e0180355.

49. Feketea, S Tsabouri (2017) Common food colorants and allergic reactions in children: Myth or reality. Food Chem 230: 578-588.

50. Kleinman RE, Brown RT, Cutter, et al. (2011) A research model for investigating the effects of artificial food colorings on children with ADHD. Pediatrics 127: 1575-1584.

51. Tanaka T, Osamu Takahashi, Akiko Inomata, et al. (2012) Reproductive and neurobehavioral effects of brilliant blue FCF in mice. Birth Defects Res B Dev Reprod Toxicol 95: 395-409.

52. EFSA (European Food Safety Authority) (2011) Scientific opinion on the re-evaluation of erythrosine (E127) as a food additive. EFSA Panel on Food Additives and Nutrient Sources added to Food. EFSA 9: 1854.

53. Dalal A, MK Poddar (2010) Involvement of high plasma corticosterone status and activation of brain regional serotonin metabolism in long-term erythrosine-induced rearing motor hyper activity in young adult male rats. Toxicol Mech Methods 20: 287-297.

54. Bawazir AE (2016) Effects of food colour allura red (No. 129) on some neurotransmitter, antioxidant functions and bioelement contents of kidney and brain tissues in male albino rats. Life Science Journal 13: 10-17.

55. Noorafshan, Maedeh Hashemi, Saied Karbalay-Doust, et al. (2018) High dose allura Red, rather than the ADI dose, induces structural and behavioral changes in the medial prefrontal cortex of rats and taurine can protect it. Acta Histochem 120: 586-594.

56. Gao, Chunmei Li, Jingyu shen, et al. (2011) Effect of food azo dye tartrazine on learning and memory functions in mice and rats, and the possible mechanisms involved. J Food Sci 76: 125-129.

57. Mohamed, Azza AA Galal, Yaser HA Elewa (2015) Comparative protective effects of royal jelly and cod liver oil against neurotox- ic impact of tartrazine on male rat pups brain. Acta Histochemica 117: 649-658.

58. Bhatt, Krati Vyas, Shakuntala Singh, et al. (2018) Tartrazine induced neurobiochemical alterations in rat brain sub-regions. Food and Chemical Toxicology 113: 322-327.

59. Alsalman Nouf, Abdul aziz Aljafari, Tanveer A Wani, et al. (2019) High-Dose Aspirin Reverses Tartrazine-Induced Cell Growth Dysregulation Independent of p53 Signaling and Antioxidant Mechanisms in Rat Brain. Biomed Res Int.

60. El-Sakhawy MA, Dina W Mohamed, Yasmine H Ahmed (2019) Histological and immunohistochemical evaluation of the effect of tartrazine on the cerebellum, submandibular glands, and kidneys of adult male albino rats. Environ Sci Pollut Res Int 26: 9574-9584.

61. https://efsa.onlinelibrary.wiley.com/doi/epdf/10.2903/j. efsa.2014.3765

62. van Hooft J (2002) Fast Green FCF (Food Green 3) inhibits synaptic activity in rat hippocampal interneurons. Neuroscience Letters 318: 163-165.

63. Yang J, Rongjun Liu, Fan Lu, et al. (2019) Fast Green FCF attenuates lipopolysaccharide-induced depressive-like behavior and downregulates TLR4/Myd88/NF-kappaB signal pathway in the mouse hippocampus. Front Pharmacol 10: 501.

64. Kanarek RB (2011) Artificial food dyes and attention deficit hyperactivity disorder. Nutr Rev 69: 385-391.

65. Behl M, Kristen Ryan, Jui-Hua Hsieh, et al. (2019) Screening for developmental neurotoxicity at the national toxicology program: The future is here. Toxicol Sci 167: 6-14.

66. Sontag TA, Tucha O, Walitza S, et al. (2010) Animal models of attention deficit/hyperactivity disorder (ADHD): A critical review. Atten Defic Hyperact Disord 2: 1-20.

67. Cortese Samuele, Maite Ferrin, Daniel Brandeis, et al. (2015) Cognitive training for attention-deficit/hyperactivity disorder: meta-analysis of clinical and neuropsychological outcomes from randomized controlled trials. Journal of the American Academy of Child and Adolescent Psychiatry 54: 164-174.

68. Holmes Joni, Kerry A Hilton, Maurice Place, et al. (2014) Children with low working memory and children with ADHD: same or different? Front Hum Neurosci 8: 976.

69. Kirkland AE, Langan MT, Holton KF (2020) Artificial food coloring affects EEG power and ADHD symptoms in college students with ADHD: a pilot study. Nutritional Neuroscience. Published online: 01 Mar 2020.

70. Nuwer MR, Buchhalter J, Shepard KM (2016) Quantitative EEG in attention-deficit/hyperactivity disorder: A companion payment policy review for clinicians and payers. Neurology: Clinical Practice 543-548.

71. https://www.apa.org/monitor/2010/09/trials.aspx

72. Hartling L, Ospina M, Liang Y, Dryden DM, Hooton N, Seida JK, Klassen TP (2009) Risk of bias versus quality assessment of randomised controlled trials: cross sectional study. BMJ 339:b4012.

73. Emser TS, Johnston BA, Steele J, et al. (2018) Assessing ADHD symptoms in children and adults: Evaluating the role of objective measures. Behav Brain Funct 14: 11.

74. Cochran Consumer Network (2019) What is systematic review?

75. Jørgensen L, Paludan-Müller AS, Laursen DRT, et al. (2016) Evaluation of the Cochrane tool for assessing risk of bias in randomized 
Citation: Llewellyn GC, Penberthy JK, Parker JM (2020) Food Color Additives in the US Food Supply: Review of Neurobehavioral Safety. J Pediatr Neurol Neurosci 4(1):55-72

clinical trials: overview of published comments and analysis of user practice in Cochrane and non-Cochrane reviews. Syst Rev 5: 80.

76. Higgins JPT, Altman DG, Gøtzsche PC, et al. (2011) The Cochrane Collaboration's tool for assessing risk of bias in randomised trials. BMJ. 343:d5928.

77. Park M, Hee Ra Park, So Jung Kim, et al. (2009) Risk assessment for the combinational effects of food color additives: Neural progenitor cells and hippocampal neurogenesis. J Toxicol Environ Health A 72: 1412-1423.

78. Ceyhan BM, Fatih Gultekin, Duygu Kumbul Doguc, et al. (2013) Effects of maternally exposed coloring food additives on recep- tor expressions related to learning and memory in rats. Food Chem Toxicol 56: 145-148.

79. Doguc DK, Betul Mermi Ceyhan, Mustafa Ozturk, et al. (2013) Effects of maternally exposed colouring food additives on cognitive performance in rats. Toxicol Ind Health 29: 616-623.

80. Doguc DK, Firdevs Aylak, Ilter Ilhan, et al. (2015) Are there any remarkable effects of prenatal exposure to food colourings on neurobehaviour and learning process in rat offspring? Nutr Neurosci 18: 12-21.

81. Erickson ZT, Erin A Falkenberg, Gerlinde AS Metz (2014) Lifespan psychomotor behaviour profiles of multigenerational prenatal stress and artificial food dye effects in rats. PLoS One 9: e92132. 